\title{
The specialty choices of graduates from Brighton and Sussex Medical School: a longitudinal cohort study
}

\author{
Katherine Woolf ${ }^{*}$, Caroline Elton ${ }^{2}$ and Melanie Newport ${ }^{3}$
}

\begin{abstract}
Background: Since 2007 junior doctors in the UK have had to make major career decisions at a point when previously many had not yet chosen a specialty. This study examined when doctors in this new system make specialty choices, which factors influence choices, and whether doctors who choose a specialty they were interested in at medical school are more confident in their choice than those doctors whose interests change post-graduation.

Methods: Two cohorts of students in their penultimate year at one medical school ( $n=227 / 239)$ were asked which specialty interested them as a career. Two years later, 210/227 were sent a questionnaire measuring actual specialty chosen, confidence, influence of perceptions of the specialty and experiences on choice, satisfaction with medicine, personality, self-efficacy, and demographics. Medical school and post-graduation choices in the same category were deemed 'stable'. Predictors of stability, and of not having chosen a specialty, were calculated using bootstrapped logistic regression. Differences between specialties on questionnaire factors were analysed.

Results: $50 \%$ responded ( $n=105 / 277 ; 44 \%$ of the 239 Year 4 students). $65 \%$ specialty choices were 'stable'. Factors univariately associated with stability were specialty chosen, having enjoyed the specialty at medical school or since starting work, having first considered the specialty earlier. A regression found doctors who chose psychiatry were more likely to have changed choice than those who chose general practice. Confidence in the choice was not associated with stability. Those who chose general practice valued lifestyle factors. A psychiatry choice was associated with needing a job and using one's intellect to help others. The decision to choose surgical training tended to be made early. Not having applied for specialty training was associated with being lower on agreeableness and conscientiousness.

Conclusion: Medical school experiences are important in specialty choice but experiences post-graduation remain significant, particularly in some specialties (psychiatry in our sample). Career guidance is important at medical school and should be continued post-graduation, with senior clinicians supported in advising juniors. Careers advice in the first year post-graduation may be particularly important, especially for specialties which have difficulty recruiting or are poorly represented at medical school.
\end{abstract}

Keywords: Careers, Specialty choice, Longitudinal, Experience

\footnotetext{
* Correspondence: k.woolf@ucl.ac.uk

'University College London Medical School (UCLMS), Room GF/664, Royal

Free Hospital, London NW3 2PF, UK

Full list of author information is available at the end of the article
} 


\section{Background}

In the United Kingdom (UK), medical school is typically a five year undergraduate course following from secondary school. Upon graduation from medical school, junior doctors have the opportunity to work in a variety of specialties before choosing one for further training. In 2005, the Modernising Medical Careers (MMC) reforms to postgraduate medical training were introduced. Junior doctors now have two years Foundation Training immediately after medical school and have to choose a specialty in their second Foundation year (FY2) i.e. 18 months after finishing medical school. Given that prior to MMC about a quarter of doctors had not decided on their final specialty at that point [1], there is concern that 18 months is too soon to make longer term specialty decisions.

The Independent Inquiry into Modernising Medical Careers conducted by Sir John Tooke ('The Tooke Report') [2] was set up to investigate some of MMC's initial difficulties. It found that many junior doctors felt that the FY2 year was too early to decide on a specialty, particularly as they may not have been exposed to many by that point. With exposure opportunities reduced, medical school experiences become more important. The Tooke Report recommends medical schools play a greater role in preparing students for career decisions. This seems prudent as a recent survey of 115 final year medical students at a London medical school found 15\% chose 'don't know' as their career option out of a list of 15 broad groups and this option was the second most popular after general practice (family medicine) [3]. A study at Liverpool medical school found that about $20 \%$ of final year medical students did not know what specialty to choose [4].

Specialty choices are often influenced by medical school experiences. Goldacre and colleagues [1] asked a large number of junior doctors one to two years after graduation in 2000 and 2001 to state up to three long term career choices, and asked which factors influenced their choice 'a great deal'. Nearly half said their experience as a student, about a quarter said a particular teacher or department, and about a sixth said experience prior to medical school. Experiences can inform career choice because they are positive or negative. A small pre-MMC longitudinal study of graduates of a UK medical school found that about half of junior doctors in their first or second year post-graduation expressed a strong interest in the same specialty they had previously expressed a strong interest in during their fourth year of medical school, and less than one percent was strongly attracted to a specialty they had been very uninterested in at medical school [5].

Specialty choice can also be influenced by a other factors, including gender [6], personality [7], perceptions about job-related factors such as work-life balance [8], not to mention unexpected opportunity and luck; and as such, trying to predict medical careers is notoriously difficult [9]. The more that is known about the factors that underpin specialty choice however, the more it may be possible to point out these key factors to medical students and junior doctors as part of careers support activities that help this group make robust decisions.

The current study followed two cohorts of Brighton and Sussex Medical School (BSMS) graduates, who had completed a formative career planning exercise during Year 4 of medical school. They were followed up at the point that they made their specialty applications in their second Foundation Year (FY2). We aimed to compare graduates' Year 4 specialty interests with their self-reported specialty application choices (or lack thereof) and to investigate which psychological, educational, and demographic factors related to stability of specialty choice. Research questions were:

1. Do graduates' specialty choices change from Year 4 to Foundation Year 2 (FY2)?

2. Which experiential, psychological and demographic factors relate to choice of specialty and stability of choice over time?

3. Is stability of choice related to confidence in choice?

4. Which factors predict not having chosen a specialty at FY2?

\section{Methods}

\section{Participants and procedure}

In 2007 and 2008, Year 4 students at Brighton and Sussex Medical School (BSMS) completed a formative career planning exercise in which they wrote the names of two specialities they were interested in as a future career (see [10] for details).

In December 2009 and 2010 these students, now graduates, were emailed an invitation to complete an online questionnaire, the first page of which was a consent form (further details about the questionnaire below). To reduce bias [11] questionnaires were administered after the closing date for specialty applications had passed, but before shortlisting. Three email reminders were sent and non-respondents were telephoned once to check they had received the email. In 2010, 13 respondents were chosen at random to receive a $£ 30$ book voucher incentive.

\section{Questionnaire}

The questionnaire measured which specialties participants had applied for, their preferred choice, their confidence that they would be successful in their preferred choice, and their confidence that their preferred choice was right for them. 
To assess general satisfaction, participants were asked how often they had considered leaving medicine in the last year (never, once or twice, monthly, weekly or daily).

To explore the role of previous experience, participants were asked:

- their favourite and least favourite medical school placements

- how much 10 experiences had influenced their choice (3 point scale)

- whether they had been dissuaded from entering a specialty (5 point scale)

- when they had first considered and definitely decided on their specialty (before medical school, during medical school, during FY1, during FY2, still undecided)

Participants rated on a 3 point scale how much 23 aspects of their chosen specialty (including lifestyle factors, prestige, job security and extent of patient contact) had influenced their choice.

A 15 -item version of a big 5 personality questionnaire $[12,13]$ and a 10-item measure of general self-efficacy [14] were included.

The questionnaire was piloted on a convenience sample of junior doctors, and altered in light of their feedback.

\section{Coding of freetext specialties}

Specialties were coded verbatim. 43 specialties were initially categorised into: hospital medical, paediatrics, accident and emergency, surgery, obstetrics and gynaecology, anaesthetics, radiology, clinical oncology, pathology, psychiatry, general practice, public health, and 'other medical'[15]. Clinical oncology and 'other medical' were subsumed into hospital medical, and public health was expanded to included research. Anaesthetics and emergency medicine specialty training are covered by the specialty training path Acute Care Common Stem (ACCS), so ACCS, anaesthetics, and emergency medicine were combined into a single category. The final ten categories were: acute care, hospital medicine, surgery, obstetrics and gynaecology, psychiatry, general practice, paediatrics, pathology, public health and research, radiology. This broadly corresponds to the 15 specialties that graduates could apply to in 2011 [16].

\section{Statistical analysis}

All analyses were performed in SPSS v20.

\section{Perceptions of specialty chosen}

The 23 items measuring perceptions of the specialty choice were factor-analysed using a Varimax rotation. The scree plot indicated the presence of three to five factors.
Three, four and five factor solutions were attempted, and a four factor solution chosen (See Table 1).

Factor 1 'Lifestyle'. High scoring individuals valued having a life outside of medicine, meeting family commitments, and job flexibility and autonomy.

Factor 2 'Money and status'. High scoring individuals valued financial security and high social status.

Factor 3 'Needed a job'. This was a factor relating to a negative choice. High scoring individuals were likely to have chosen a specialty they were likely to get a job in.

Factor 4 'Using intellect to help others'. High scoring individuals valued intellectually stimulating careers in which they could make a difference to people's lives, either directly via patient contact, or indirectly via research.

\section{Non-parametric testing and bootstrapping}

Bootstrapping is a non-parametric statistical technique used to estimate the sampling distribution of a statistic by resampling with replacement many times the data from one sample [17]. Bootstrapping does not make assumptions about the population and can therefore be used when the sample is small and when assumptions of Normality are violated. Bootstrapping was used to estimate $95 \%$ confidence intervals (CI) for means and standard errors, and regression coefficients, as well as for medians and percentages, as described in the SPSS bootstrapping handbook [18]. Bootstrapping was typically performed using 1,000 random bootstrap samples. As a sensitivity test, and for ease of interpretation, conventional non-parametric statistical tests (Chi-squared, Mann Whitney U, and Kruskal Wallis) were also used. There results of both are presented.

\section{Stability of specialty choice from Year 4 to FY2}

The stability of specialty choice from Year 4 of medical school to FY2 was the main outcome variable of interest. A categorical variable Stability was created [2=at least one Year 4 specialty in the same category as the FY2 specialty ('stable choice'); 1 = no Year 4 choices in the same category as the FY2 choice ('different choice'); $0=$ no specialty chosen at FY2].

Respondents with a 'stable choice' were compared to those with a 'different choice' (those who had not chosen a specialty were excluded).

\section{Differences between specialties}

Respondents who had chosen different specialties at FY2 were compared (those who had not chosen a specialty were excluded).

\section{No specialty chosen at FY2}

A No Specialty variable was created by combining 'stable choice' and 'different choice', and comparing this category to those who had not chosen a specialty. 


\begin{tabular}{|c|c|c|c|c|}
\hline Item name & Lifestyle & $\begin{array}{l}\text { Money and } \\
\text { status }\end{array}$ & $\begin{array}{l}\text { Needed } \\
\text { a job }\end{array}$ & $\begin{array}{l}\text { Using intellect } \\
\text { to help others }\end{array}$ \\
\hline Suits my personality & 0.525 & & & 0.439 \\
\hline Suits my skills \& aptitude & 0.287 & & & 0.495 \\
\hline Intellectually stimulating & -0.321 & 0.320 & & 0.667 \\
\hline Change people's lives & & & & 0.613 \\
\hline Opportunity for research & & & & 0.659 \\
\hline Right patient contact & & & 0.204 & 0.644 \\
\hline New technologies & -0.274 & 0.558 & & 0.321 \\
\hline Training opportunities & & 0.319 & 0.290 & 0.503 \\
\hline Easy to get job & 0.419 & & 0.684 & \\
\hline Needed job this year & & & 0.801 & \\
\hline Good promotion & & 0.409 & 0.521 & \\
\hline Job security & 0.477 & 0.574 & 0.281 & \\
\hline Can change specialty later & & 0.457 & 0.294 & \\
\hline Well paid & 0.504 & 0.692 & & \\
\hline Well regarded & & 0.780 & & 0.262 \\
\hline Private practice & & 0.701 & & \\
\hline Geographic location & 0.539 & 0.379 & 0.276 & \\
\hline On call \& shifts & 0.822 & & & \\
\hline Family friendly & 0.878 & & & \\
\hline Outside interests & 0.862 & & & \\
\hline Job control & 0.853 & & & \\
\hline Less discrimination & & 0.366 & 0.213 & 0.305 \\
\hline Best of bad bunch & & & 0.880 & \\
\hline
\end{tabular}

Higher numbers indicate a closer association between the item score and the factor score e.g. between "private practice" and "Money \& Status" (items with loadings $>0.6$ are in bold). Negative signs indicate a high score on the item is associated with a low score on the factor.

Univariate analyses were conducted as follows:

- Categorical variables (cohort, specialty chosen, sex, ethnicity, when first considered specialty, when decided to apply for specialty): chi-squared tests were used to compare proportions in each group, and the bootstrapped $95 \%$ confidence intervals of proportions of respondents in each group were compared.

- Continuous variables (confidence, personality, general self-efficacy, perceptions of the specialty): bootstrapped independent t-tests and one-way ANOVAs, Mann Whitney U and Kruskal Wallis tests were used to compare groups.

- Ordinal variables with three levels (satisfaction with medicine as a career, previous experiences, whether dissuaded from entering a specialty): bootstrapped group medians were compared, and Mann Whitney $\mathrm{U}$ tests were also performed.

- Bootstrapped Pearson's correlations were calculated to estimate the strength and direction of the relationships between personality, self-efficacy, and confidence.

Logistic regression was used to identify the independent predictors of the Stability and No Specialty variables from those factors found to be statistically significant in the univariate analyses. Bootstrapping was used to estimate $\mathrm{p}$ values and the $95 \%$ confidence intervals for the regression coefficients and standard errors.

\section{Ethical approval}

Ethical approval for the study was granted by the UCL Ethics Committee (ref: 0511/004 and 0511/005).

\section{Results}

Sample

All 96 students in the 2007 Year 4 cohort completed the career planning exercise, and 43/96 (45\%) responded to the questionnaire.

131/143 students in the 2008 Year 4 cohort completed the career planning exercise. Email addresses were available 
for $114 / 143$, of who $62 / 114$ (54\%) responded to the questionnaire.

There were no significant differences between cohorts in stability of choice $(\chi 2=0.03 ; \mathrm{df}=1 ; \mathrm{p}=0.857)$ and so the 2007 and 2008 cohorts were combined for analysis.

Of 239 Year 4 students, 227 completed the career planning exercise in Year 4, and 210 had email addresses for follow-up in FY2. Of those 210, 105 gave usable responses to the questionnaire, giving a response rate of $50 \%$ (44\% of the 239 eligible to take part in the career planning exercise).

The sample of 105 comprised 36 men and 66 women (3 missing); 81/101 of white ethnicity, 11 of Asian ethnicity (including Chinese), 4 of mixed ethnicity, and 4 of black ethnicity (5 missing). The Asian, black, mixed, and Chinese groups were combined into a Black and Minority Ethnic (BME; $\mathrm{n}=20$ ) group for analysis. The age range was 24 to 41 years, median 25 (4 missing).

\section{Descriptive statistics}

\section{Year 4 specialty interests}

The two Year 4 specialty interests chosen by each student were summed to give an overall number of times each specialty was selected (see Table 2).

\section{Foundation Year 2 specialty choice}

81/105 respondents had applied for specialty training. 77 respondents reported both their Year 4 and FY2 choices. $34 / 77$ had applied to more than one specialty, 13/34 had a second choice in the same category as their first choice. We refer to respondents' preferred (first) choice only.

Descriptive statistics for categorical and ordinal questionnaire variables are reported in Table 3. Distributions and descriptive statistics for continuous questionnaire variables are reported in Figure 1. The reported influence that

Table 2 The specialties selected, in no particular order, by respondents when they were in Year 4 of medical school (sum in parentheses)

\begin{tabular}{ll}
\hline Specialty & N (sum of two year $\mathbf{4}$ interests) \\
\hline Acute care common stem & $14+10(24)$ \\
General practice & $23+27(50)$ \\
Medical specialties & $23+22(45)$ \\
O\&G & $10+9(19)$ \\
Paediatrics & $11+6(17)$ \\
Pathology & 0 \\
Psychiatry & $5+7(12)$ \\
Public health and research & $2+2(4)$ \\
Radiology & $1+1(2)$ \\
Surgical specialties & $7+9(16)$ \\
Missing & $9+12(21)$ \\
\hline
\end{tabular}

Missing $n=9$.
10 experiences had on participants' specialty choices is shown in Figure 2.

\section{Predictors of stability of choice Specialty chosen}

Stability varied significantly by specialty $(\chi 2=17.99 ; \mathrm{df}=7$; $\mathrm{p}=0.012$ ). See Table 4 .

\section{Experiences}

Respondents with a stable choice were more influenced by enjoying the specialty at medical school [median 'stable choice' $=3$ (bootstrapped $95 \% \mathrm{CI}=2,3$ ); median 'different choice' = 2 (bootstrapped 95\% CI =2,3); Mann Whitney U: $\mathrm{z}=-1.7 ; \mathrm{p}=.08$ ].

Respondents whose choice changed were more influenced by enjoying the specialty since qualifying [median 'stable choice' $=3$ (bootstrapped 95\% CI =2,3); median 'different choice' = 3 (bootstrapped 95\% CI =3,3); Mann Whitney $\mathrm{U}: \mathrm{z}=-2.1 ; \mathrm{p}=0.03]$.

\section{Being dissuaded from choosing a specialty}

Respondents with a stable choice were less likely to have been dissuaded [not dissuaded: 'stable choice' $=51 \%$ (bootstrapped 95\% CI =37, 65); 'different choice' $=26 \%$ (bootstrapped 95\% CI = 10,44); Mann Whitney U: $\mathrm{z}=-1.8$; $\mathrm{p}=0.078$ ] ['stable choice' median $=2$ ('probably not dissuaded') (bootstrapped 95\% CI $=2,4$ ); 'different choice' median $=4$ ('probably dissuaded') (bootstrapped 95\% CI $=3,4)$ ].

\section{When first considered specialty}

Respondents whose choice changed were more likely to have first considered their specialty in Foundation Year 1 ['stable choice' $=12 \%$ (bootstrapped 95\% CI $=4,22$ ); 'different choice' $=44 \%$ (bootstrapped 95\% CI =26,64)]; $\left.\chi^{2}=10.6 ; \mathrm{df}=3 ; \mathrm{p}=0.014\right]$.

No other factors were significantly univariately related to Stability.

\section{Regression}

Specialty chosen was the only significant independent predictor of Stability. Those who chose psychiatry were more likely than those who chose general practice to change their choice $[\mathrm{B}=-3.81$ (bootstrapped 95\% $\mathrm{CI}=-27.76,-0.95$ ); odds ratio $=0.003$; bootstrapped $\mathrm{p}=0.02]$. See Table 5 . Paediatrics split the outcome variable completely (all those who chose paediatrics had a stable choice), so it was excluded from the regression.

\section{Differences between respondents who chose different specialties}

\section{Demographics and specialty chosen}

General practice was more popular with black and minority ethnic doctors than surgical specialties, $O \& G$, and 
Table 3 Descriptive statistics (with percentages in parenthesis) for the categorical and ordinal questionnaire variables

Variable Descriptive statistics (percentages)

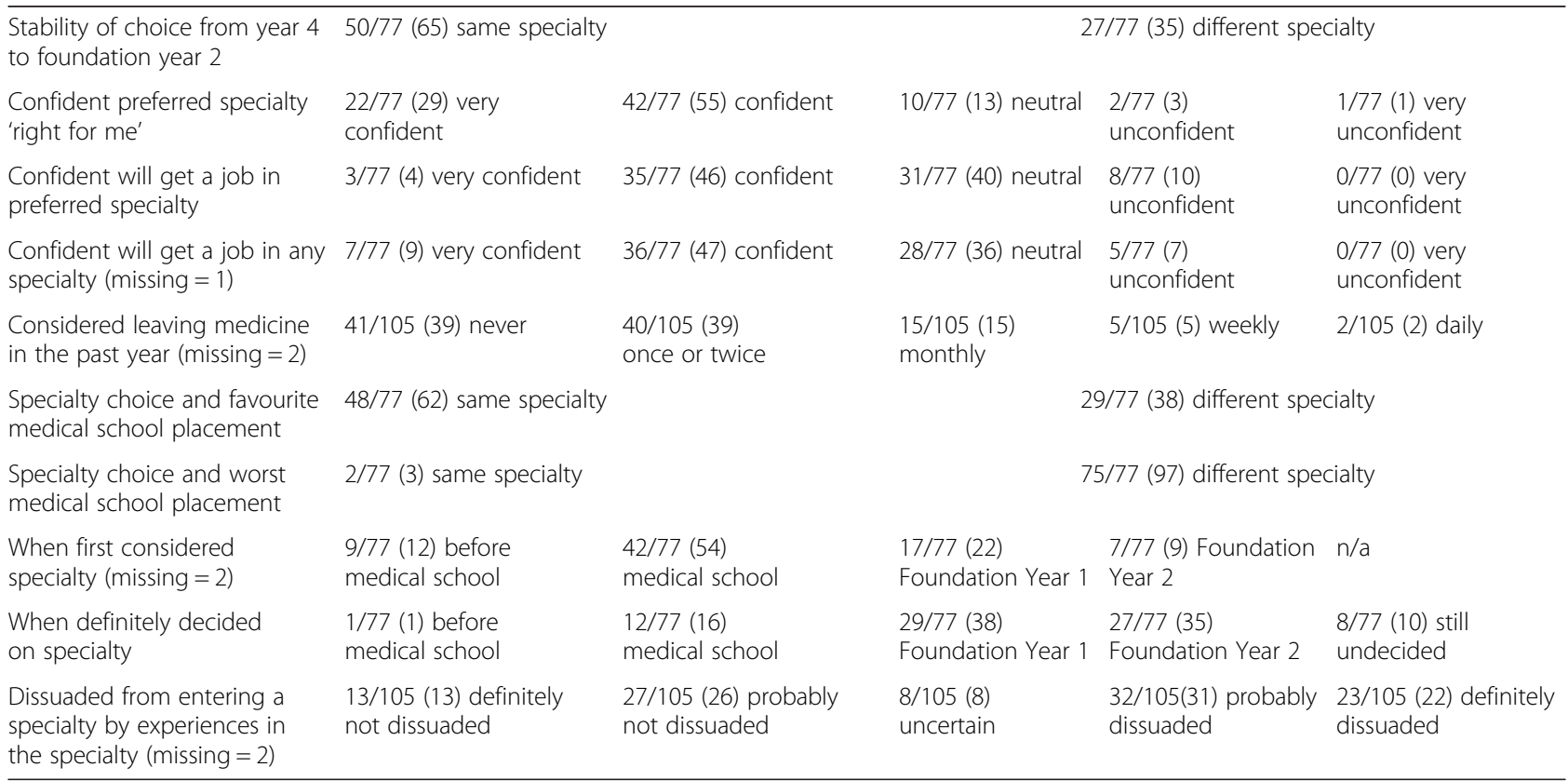

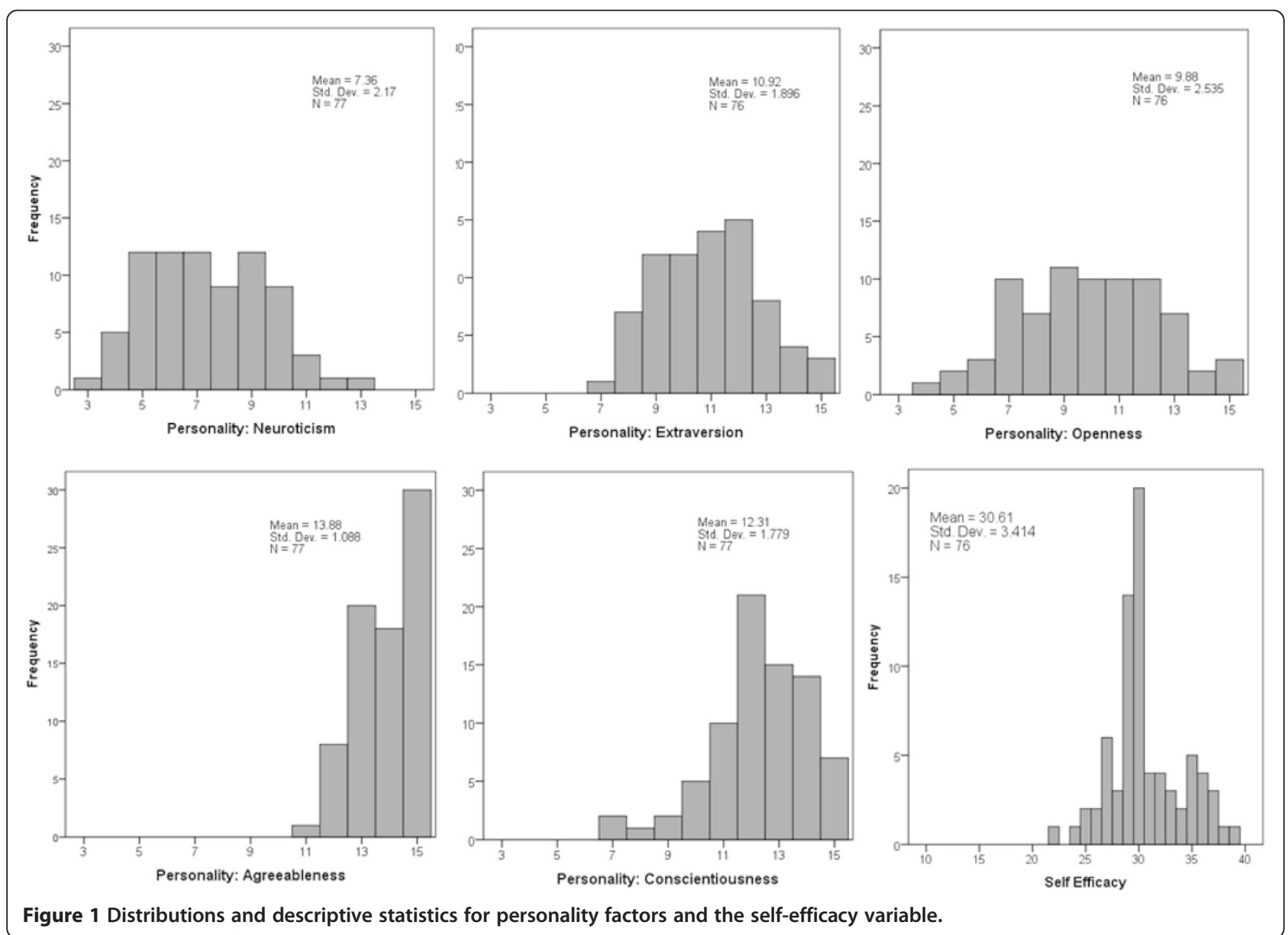




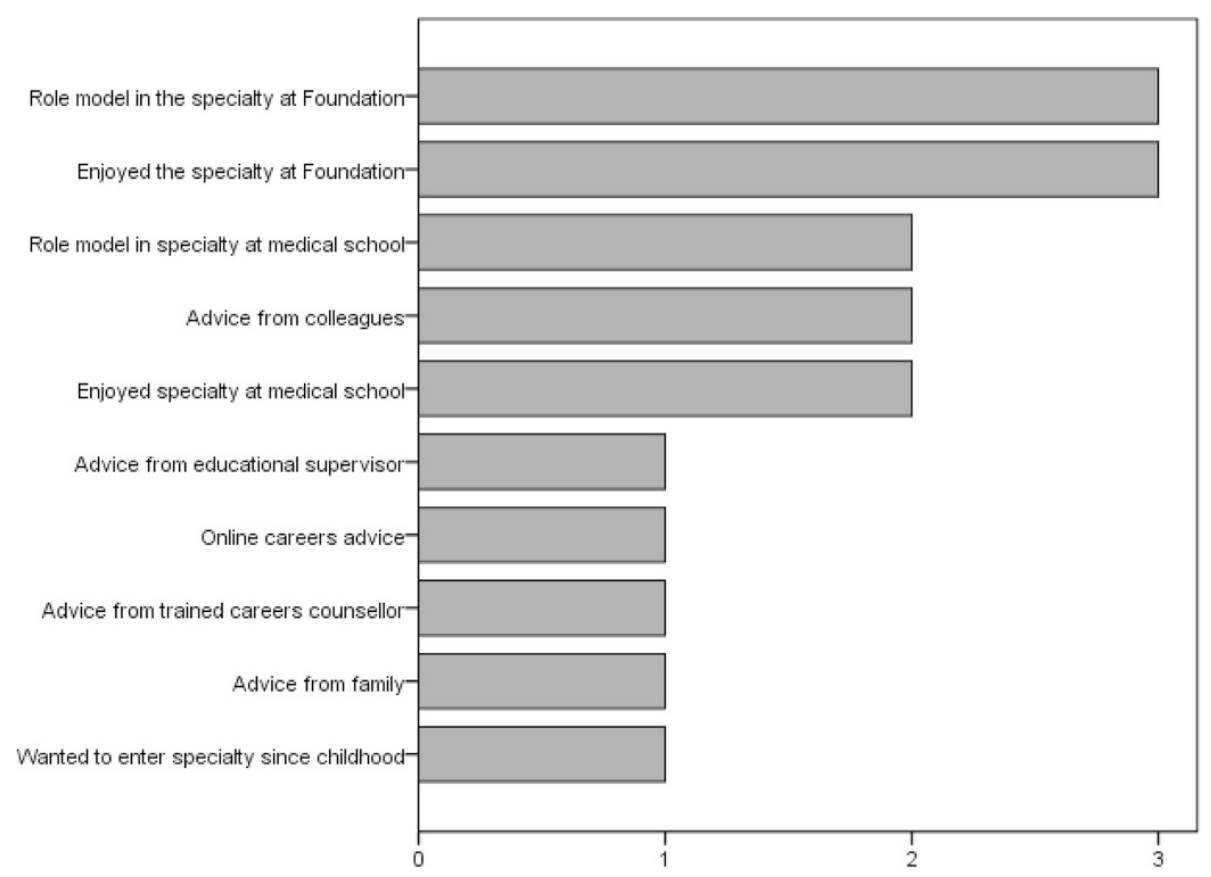

Figure 2 Median ratings of how influential each experience was in choosing a specialty post-graduation.

paediatrics, which were not chosen by any BME respondents [GP: 80\% white (bootstrapped 95\% CI $=60,96$ )].

\section{Confidence and specialty chosen}

Respondents who chose surgical specialties (mean confidence $=2.8$; bootstrapped $95 \% \mathrm{CI}=2.4,3.4)$ were less confident that they would get a job in their preferred specialty compared to respondents who chose medical specialties $($ mean confidence $=3.7$; bootstrapped $95 \% \mathrm{CI}=3.3,4.0$ ) and psychiatry (mean confidence $=3.7 ;$ bootstrapped $95 \% \mathrm{CI}=3.2,4.0)[\mathrm{F}(6,74)=2.5 ; \mathrm{p}=0.028]$.

\section{When decided to enter specialty}

Respondents who chose surgical specialties on average made their decision at medical school, whereas all others except O\&G made their decision later or were still undecided [median surgical specialties $=2$ (bootstrapped 95\% $\mathrm{CI}=2,2$ ); median $\mathrm{O} \& \mathrm{G}=3.5$ (bootstrapped $95 \% \mathrm{CI}=1,4$ );

Table 4 Stability of specialty choice from year 4 medical school to foundation year 2 post-graduation

\begin{tabular}{|c|c|c|c|}
\hline \multirow{2}{*}{$\begin{array}{l}\text { FY2 specialty choice } \\
\text { Paediatrics }\end{array}$} & \multicolumn{2}{|c|}{ Year 4 specialty choice } & \multirow{2}{*}{$\begin{array}{l}\text { Percent (bootstrapped } 95 \% \text { confidence interval } \\
0\end{array}$} \\
\hline & Different & 0 & \\
\hline & Same & 4 & $100.0(100.0,100.0)$ \\
\hline \multirow[t]{2}{*}{ General practice } & Different & 4 & $16.0(4.0,32.0)$ \\
\hline & Same & 21 & $84.0(68.0,96.0)$ \\
\hline \multirow[t]{2}{*}{ O\&G } & Different & 1 & $25.0(0.0,75.0)$ \\
\hline & Same & 3 & $75.0(25.0,100.0)$ \\
\hline \multirow[t]{2}{*}{ Medical specialties } & Different & 5 & $27.8(11.1,50.0)$ \\
\hline & Same & 13 & $72.2(50.0,88.9)$ \\
\hline \multirow[t]{2}{*}{ Surgical specialties } & Different & 4 & $57.1(16.7,87.5)$ \\
\hline & Same & 3 & $42.9(12.5,83.3)$ \\
\hline \multirow[t]{2}{*}{ Psychiatry } & Different & 4 & $66.7(33.3,100.0)$ \\
\hline & Same & 2 & $33.3(0.0,66.7)$ \\
\hline \multirow[t]{2}{*}{ Acute care } & Different & 8 & $66.7(38.5,92.3)$ \\
\hline & Same & 4 & $33.3(7.7,61.5)$ \\
\hline
\end{tabular}

Radiology and public health excluded as only one respondent chose each. Bootstrapped $95 \%$ confidence intervals for the percentages show Paediatrics was significantly more stable than all specialties except O\&G, and General Practice was significantly more stable than Psychiatry and Acute Care. 
Table 5 Factors related to stability of specialty choice from Year 4 medical school to Foundation Year $2(0=$ 'different choice; 1 = 'stable choice')

\begin{tabular}{|c|c|c|c|c|c|c|}
\hline Predictors & & B (bootstrapped 95\% Cl) & $\begin{array}{l}\text { Bootstrapped } \\
\text { standard error }\end{array}$ & $p$ value & $\begin{array}{l}\text { Bootstrapped } \\
\text { p value }\end{array}$ & $\begin{array}{l}\text { Odds } \\
\text { ratio }\end{array}$ \\
\hline $\begin{array}{l}(1=\text { before medical school; } 2=\text { at medical } \\
\text { school; } 3=\text { at FY1; } 4=\text { at FY2) }\end{array}$ & First considered specialty & $-0.54(-2.49,0.93)$ & 1.60 & 0.278 & 0.58 & 0.310 \\
\hline $\begin{array}{l}(1=\text { no influence; } 2 \text { = moderate influence; } \\
3=\text { strong influence) }\end{array}$ & $\begin{array}{l}\text { Enjoyed specialty at } \\
\text { medical school }\end{array}$ & $0.95(-0.45,3.71)$ & 2.58 & 0.089 & 2.57 & 0.121 \\
\hline \multirow{5}{*}{$\begin{array}{l}\text { Reference category: General Practice } \\
\text { (Paediatrics \& Radiology excluded) }\end{array}$} & Acute care & $-2.24(-20.19,0.28)$ & 6.05 & 0.026 & 0.11 & 0.027 \\
\hline & Medical specialties & $-0.53(-4.32,2.36)$ & 3.98 & 0.553 & 0.59 & 0.612 \\
\hline & Surgical specialties & $-2.66(-24.71,0.52)$ & 8.52 & 0.023 & 0.07 & 0.019 \\
\hline & Obstetrics \& Gynaecology & $-1.14(-22.19,20.07)$ & 12.31 & 0.423 & 0.32 & 0.218 \\
\hline & Psychiatry & $-3.81(-27.76,-0.95)^{*}$ & 11.96 & 0.008 & 0.02 & 0.003 \\
\hline $\begin{array}{l}(1=\text { not dissuaded } ; 2=\text { probably dissuaded; } \\
3=\text { uncertain; } 4=\text { probably not dissuaded; } \\
5=\text { not dissuaded })\end{array}$ & $\begin{array}{l}\text { Dissuaded from entering } \\
\text { a specialty by experienced } \\
\text { since starting work }\end{array}$ & $-0.33(-1.31,0.21)$ & 0.42 & 0.170 & 0.72 & 0.215 \\
\hline \multirow[t]{2}{*}{$\begin{array}{l}(1=\text { no influence; } 2 \text { = moderate influence; } \\
3 \text { = strong influence) }\end{array}$} & $\begin{array}{l}\text { Enjoyed the specialty } \\
\text { since starting work }\end{array}$ & $-0.77(-3.00,-0.03)$ & 1.79 & 0.057 & 0.46 & 0.046 \\
\hline & Constant & $3.83(-1.37,15.89)$ & 6.69 & 0.102 & 46.23 & 0.115 \\
\hline
\end{tabular}

Bootstrapping based on 976 samples. *significant at $\mathrm{p}<0.05$ in a logistic regression.

median all other specialties range $=3.5$ to 4 (bootstrapped $95 \% \mathrm{CI}$ range $=3$ to 5$\left.) ; \chi^{2}=14.5 ; \mathrm{df}=6 ; \mathrm{p}=0.024\right]$.

\section{Perceptions of the specialty}

The 'lifestyle' factor was significantly more important to those who chose general practice (mean $=1.0$; bootstrapped $95 \% \mathrm{CI}=0.8,1.3)$ than those who chose surgical specialties (mean $=-0.9$; bootstrapped $95 \% \mathrm{CI}=-1.3,-0.5)$, O\&G (mean $=-0.7$; bootstrapped $95 \% \mathrm{CI}=-1.2,-0.5$ ), and medical specialties (mean $=-0.4$; bootstrapped $95 \% \mathrm{CI}=-0.7$,$0.3),[\mathrm{F}(6,64)=13.5 ; \mathrm{p}<0.001]$.

The negative 'had to do something' factor was significantly more important to those who chose psychiatry (mean $=1.3$; bootstrapped $95 \% \mathrm{CI}=0.1,2.9)$ than those who chose surgery (mean $=-0.4$; bootstrapped $95 \% \mathrm{CI}=-0.6,-0.2$ ), $[\mathrm{F}(6,64)=2.3 ; \mathrm{p}=0.043]$.

The factor 'using one's intellect to help others was significantly more important to those who chose psychiatry (mean $=0.8$; bootstrapped 95\% CI $=0.5,1.1$ ) than those who chose general practice (mean $=-0.5$; bootstrapped $95 \% \mathrm{CI}=-0.10,-0.06) ;[\mathrm{F}(6,64=2.07 ; \mathrm{p}=0.053]$.

\section{Personality}

Respondents who chose acute care (mean $=12.7$; bootstrapped $95 \% \mathrm{CI}=11.8,13.6)$ were significantly more extroverted than those who chose medical specialties ( mean $=10.8$; bootstrapped $95 \% \mathrm{CI}=10.0,11.5)$, psychiatry (mean $=10.5$; bootstrapped $95 \% \mathrm{CI}=9.3,11.7$ ), and general practice $($ mean $=10.0$; bootstrapped $95 \% \mathrm{CI}=9.4,10.6$ ) $[\mathrm{F}(6,67)=4.03 ; \mathrm{p}=0.002]$.

No other factors differed significantly between respondents choosing difference specialties at FY2.

\section{Predictors of not having chosen a specialty}

The 80 respondents who had chosen a specialty (including the three without a Year 4 choice and thus excluded from the Stability analyses) were compared to the 25 who had not chosen a specialty.

\section{Cohort}

More respondents in the 2008 cohort had not chosen a specialty $(\chi 2=3.9 ; \mathrm{df}=1 ; \mathrm{p}=0.048)$.

\section{Satisfaction}

Respondents who had not chosen a specialty were twice as likely to have considered leaving medicine monthly or more in the last year [considered leaving monthly or more: no specialty $=38 \%$ (bootstrapped $95 \% \mathrm{CI}=21,58$ ); specialty chosen $=17 \%$ (bootstrapped $95 \% \mathrm{CI}=8,25)$; Mann Whitney $\mathrm{U}: \mathrm{z}=-1.87 ; \mathrm{p}=0.06]$.

\section{Personality}

Respondents who had not chosen a specialty were significantly higher on neuroticism $[\mathrm{t}(99)=2.1$; bootstrapped $\mathrm{p}=0.047$; mean difference $=1.2(95 \% \mathrm{CI}=0.1,2.3)]$; lower on agreeableness $[\mathrm{t}(99)=-2.6$; bootstrapped $\mathrm{p}=0.032$; mean difference $=-0.7(95 \% \mathrm{CI}=-1.4,-0.1)]$; and lower on conscientiousness $[\mathrm{t}(99)=-3.4$; bootstrapped $\mathrm{p}=0.002$; mean difference $=-1.5(95 \% \mathrm{CI}=-2.4,-0.6)]$.

\section{Regression}

Low agreeableness $[B=0.53$ (bootstrapped $95 \% C I=0.17$, 1.20 ); odds ratio $=1.69$; bootstrapped $\mathrm{p}=0.028]$ and low conscientiousness $[\mathrm{B}=0.40$ (bootstrapped $95 \% \mathrm{CI}=0.11$, 0.86 ); odds ratio $=1.49$; bootstrapped $\mathrm{p}=0.004]$ were the 
only significant independent predictors of not having chosen a specialty at FY2. See Table 6 .

\section{Relationship between confidence, personality, and self- efficacy}

There was a large correlation between confidence in getting a job in a chosen specialty and confidence in getting a job generally $(\mathrm{r}=0.87$; bootstrapped $95 \% \mathrm{CI}=0.77,0.93)$.

Respondents who were less extraverted were more confident they would get a job in their chosen specialty $(\mathrm{r}=-0.28$; bootstrapped $95 \% \mathrm{CI}=-0.49,-0.05)$ and generally $(r=-0.28$; bootstrapped $95 \% \mathrm{CI}=-0.48,-0.05)$.

Respondents with higher self-efficacy were lower on neuroticism ( $\mathrm{r}=-0.31$; bootstrapped $95 \% \mathrm{CI}=-0.48$, $-0.13)$, higher on extraversion $(\mathrm{r}=0.4$; bootstrapped $95 \% \mathrm{CI}=0.2,0.6$ ), and higher on conscientiousness $(r=0.39$; bootstrapped $95 \% C I=0.18,0.59)$. Selfefficacy was not related to confidence.

\section{Discussion}

This longitudinal study found that when considering groups of specialties, two thirds of BSMS graduates had a Foundation Year 2 specialty choice that had been stable since Year 4 of medical school. Unexpectedly stability was not related to confidence but it was related to the specific specialty group chosen. Specialty choice was reportedly strongly influenced by experiences within the specialty at medical school and after starting work. Half of doctors said they had been dissuaded from entering a particular specialty, and only two chose a specialty they had disliked at medical school. Perceptions of the specialty were influential, lifestyle factors were important to those applying for general practice and psychiatry, and those who chose psychiatry were also most likely to say they 'had to choose something'. General practice was popular with Black and Minority Ethnic doctors, none of who chose surgical specialties, obstetrics \& gynaecology, or paediatrics. About a quarter of doctors had not applied for specialty training, which was predicted by low agreeableness and low conscientiousness.
This is the first UK longitudinal study of medical student and junior doctors' specialty choices since the MMC reforms were made. It gathered data on doctors' actual specialty choices and prospective data on their interests at medical school, which are less biased than retrospective recollections. The small numbers of graduates from a single medical school and 50\% response rate reduces the reliability and generalisability of the results; however, they reflect findings from other studies, suggesting a broadly representative sample [6,19]. All participants had completed a formative career planning exercise at medical school, which may have made them more certain about their choices than other doctors.

The findings support the literature about the influence of experience and role models on specialty choice [20-23]. Stability of choice was not related to confidence or satisfaction generally with medicine, suggesting that change can be positive, particularly if properly supported. Career advice during medical school could encourage students to assemble a tentative short-list of specialties to explore during foundation training [24] rather than to decide on the specific specialty. However, currently applicants need to show 'commitment to specialty' by for example assembling audits and attend conferences in that specialty, which encourages early choices. As an alternative, a focus on 'depth of career planning' may be more appropriate so that applicants who have changed their minds during the foundation programme are not penalised.

In this study, senior doctors were an importance source of informal career advice, and thus may benefit from careers guidance training, particularly as, in our experience, only a small minority of junior doctors seek indepth career counselling and usually this is linked to health or performance issues, or to the desire to leave clinical practice.

A quarter of the respondents in this study had not applied for specialty training. Nationally, relatively high numbers of junior doctors take a break after foundation training, often to work abroad as a doctor, but few leave medicine at this point [25]. The significant association

Table 6 Factors related to 'not choosing a specialty' ( $0=$ no specialty chosen; $1=$ specialty chosen)

\begin{tabular}{|c|c|c|c|c|c|c|}
\hline Predictors & & B (bootstrapped 95\%Cl) & $\begin{array}{l}\text { Bootstrapped } \\
\text { Standard error }\end{array}$ & $p$ value & $\begin{array}{l}\text { Bootstrapped } \\
\text { p value }\end{array}$ & $\begin{array}{l}\text { Odds } \\
\text { ratio }\end{array}$ \\
\hline (reference: 2007 cohort) & 2008 cohort & $-0.99(-2.84,0.17)$ & 0.95 & 0.093 & 0.091 & 0.37 \\
\hline \multirow[t]{3}{*}{ Personality } & Neuroticism & $-0.10(-0.51,0.183)$ & 0.18 & 0.435 & 0.484 & 0.90 \\
\hline & Agreeableness & $0.53(0.17,1.20)^{*}$ & 0.30 & 0.021 & 0.028 & 1.69 \\
\hline & Conscientiousness & $0.40(0.11,0.86)^{*}$ & 0.20 & 0.005 & 0.004 & 1.49 \\
\hline \multirow[t]{2}{*}{$\begin{array}{l}(1=\text { monthly or less; } 2=\text { once } \\
\text { or twice; } 3=\text { never })\end{array}$} & $\begin{array}{l}\text { Satisfaction (frequency considered } \\
\text { leaving medicine in the past year) }\end{array}$ & $0.55(-0.59,1.68)$ & 0.56 & 0.169 & 0.253 & 1.73 \\
\hline & Constant & $-10.31(-23.77,0.91)$ & 6.230 & 0.017 & 0.037 & 0.00 \\
\hline
\end{tabular}

Bootstrapping based on 1,000 samples. *significant at $p<0.05$ in a logistic regression. 
between dissatisfaction with medicine and not having applied for specialty training in our study was underpinned by personality, particularly low agreeableness and low conscientiousness. Previous research has found associations between low conscientiousness, low agreeableness, and stress [26], suggesting medical students and junior doctors who experience stress more keenly than others may need additional support with making robust career decisions. Conscientiousness predicts academic performance $[27,28]$, which we did not measure in this study. It may be that those who did not apply were taking time out to improve their $\mathrm{CV}$ and improve their chances in subsequent recruitment rounds.

Although related to negative experiences, being put off a specialty can be useful for individuals looking to choose between one or more specialties. Negative experiences may be more problematic for some specialties such as psychiatry [29-31]. In our study, graduates who chose psychiatry scored significantly higher on the negative factor 'had to do something', but also on the factor 'using one's intellect to help others', and on the 'lifestyle' factor, supporting previous findings [31]. The Royal College of Psychiatrists recommend medical school rotations showcase this specialty more effectively [30]. Initiatives could also emphasise relevant positive aspects such as its potential intellectual challenges and the fact that it is possible to work at consultant level while achieving an acceptable work-life balance.

\section{Conclusions}

Despite changes that require junior doctors to choose a specialty 18 months after graduating from medical school, one of the most important influences on specialty choice remains experience in that specialty during foundation training, including the influence of role models and senior colleagues. Many graduates in our sample also had a good idea of broad type of specialty they would like to enter while still at medical school, and rated medical school experiences as highly influential. Taken together, these findings highlight the importance of starting career guidance for doctors at medical school, but also continuing it through the foundation years when final decisions are cemented. They suggest greater emphasis should be placed on ensuring that trainees have access to a wide variety of specialties, and that senior clinicians are provided with support in advising junior colleagues, particularly those with a tendency to stress. Future research could investigate the impact of career planning interventions at medical school by following up doctors who had received such interventions with those who had not, and looking at whether stability of choice from medical school to post-foundation training relates to success, both psychological and in terms of performance.

\section{Competing interests}

At the time of submission, Caroline Elton was Head of the Careers Unit at the London Deanery. Katherine Woolf was provided with funding from the London Deanery to work on this study.

\section{Authors' contributions}

CE devised the study, which was further developed by CE, MJ and KW. CE, $\mathrm{MJ}$ and KW were involved in collecting data, which were analysed by KW. KW and CE wrote the first draft, which was revised by CE, MJ and KW, who all read and approved the final version.

\section{Acknowledgements}

Thanks to Nicola Greaves and Tasmin Barnett who helped with the data collection, and to Henry Potts and Chris McManus for advising on the statistical approach.

\section{Author details}

'University College London Medical School (UCLMS), Room GF/664, Royal Free Hospital, London NW3 2PF, UK. 'London Deanery, The Careers Unit, Room ST201, Stewart House, 32 Russell Square, London WC1B 5DN, UK. ${ }^{3}$ Brighton \& Sussex Medical School, BSMS Teaching Building, University of Sussex, Brighton East Sussex BN1 9PX, UK.

Received: 6 November 2012 Accepted: 25 February 2015

Published online: 13 March 2015

\section{References}

1. Goldacre MJ, Turner G, Lambert TW. Variation by medical school in career choices of UK graduates of 1999 and 2000. Med Educ. 2004;38(3):249-58.

2. Tooke J. Aspiring to Excellence. Findings and Recommendations of The Independent Enquiry Into Modernising Medical Careers. 2008. MMC Inquiry.

3. Luther V. Career decision difficulties post foundation training. The medical student perspective. JRSM Short Rep. 2011;2(5):39.

4. Maudsley G, Williams L, Taylor D. Medical students and prospective medical students uncertainties about career intentions: cross-sectional and longitudinal studies. Med Teach. 2010;32(3):e143-51.

5. Mahoney R, Katona C, Mcparland M, Noble L, Livingston G. Shortage specialties: changes in career intentions from medical student to newly qualified doctor. Med Teach. 2004;26(7):650-4.

6. Goldacre MJ, Goldacre R, Lambert TW. Doctors who considered but did not pursue specific clinical specialties as careers: questionnaire surveys. J R Soc Med. 2012;105(4):166-76.

7. Markert RJ, Rodenhauser P, El-Baghdadi MM, Juskaite K, Hillel AT, Maron BA. Personality as a prognostic factor for specialty choice: a prospective study of 4 medical school classes. Medscape J Med. 2008;10(2):49.

8. Cleland J, Johnston PW, French FH, Needham G. Associations between medical school and career preferences in Year 1 medical students in Scotland. Med Educ. 2012:46(5):473-84.

9. McManus IC, Goldacre MJ. Predicting Career Destinations. In: Carter Y, Jackson NR, editors. Medical Education and Training - from theory to delivery. Oxford: Oxford University Press; 2008. p. 59-78.

10. Elton C, Newport M. The reflective elective: using the elective to develop medical students' skills in career planning. British J Hosp Med (Lond). 2008;69(7):409-11.

11. Fischhoff B. Hindsight does not equal foresight: the effect of outcome knowledge on judgment under uncertainty. J Exp Psychol Hum Percept Perform. 1975;1(3):288-99.

12. Costa PT, McCrae RR. Revised NEO personality inventory (NEO-PI-R) and NEO five-factor inventory (NEO-FFI) professional manual. Odessa, FL: Psychological Assessment Resources; 1992.

13. McManus IC, Smithers E, Partridge P, Keeling A, Fleming PR. A levels and intelligence as predictors of medical careers in UK doctors: 20 year prospective study. BMJ. 2003;327(7407):139-42.

14. Schwarzer R, Jerusalem M. Generalized Self-Efficacy Scale. Measures in health psychology: A user's portfolio. Causal and control beliefs. Windsor: NFER-Nelson; 1995. p. 35-7.

15. Goldacre ML, Laxton L, Lambert TW. Medical graduates' early career choices of specialty and their eventual specialty destinations: UK prospective cohort studies. BMJ. 2010;341:c3199. http://dx.doi.org/10.1136/bmj.c3199. 
16. Carr A, Sullivan E, Buggle S, Hamilton P. Specialty training at ST1 and CT1 in England. BMC Careers. 30 ${ }^{\text {th }}$ November 2011. http://careers.bmj.com/careers/ advice/view-article.html?id=20005662

17. Mooney CZ, Duval RD. Bootstrapping: a nonparametric approach to statistical inference (Quantitative Applications in the Social Sciences). Newbury Park, CA: Sage; 1993.

18. IBM. IBM SPSS Bootstrapping 20. 2011. https://www.csun.edu/sites/default/ files/bootstrapping20-32bit.pdf

19. Edwards C, Lambert TW, Goldacre MJ, Parkhouse J. Early medical career choices and eventual careers. Med Educ. 1997;31(4):237-42.

20. Campos-Outcalt D, Senf J, Watkins AJ, Bastacky S. The effects of medical school curricula, faculty role models, and biomedical research support on choice of generalist physician careers: a review and quality assessment of the literature. Acad Med. 1995;70(7):611-9.

21. Ravindra P, Fitzgerald J. Defining surgical role models and their influence on career choice. World J Surg. 2011;35(4):704-9.

22. Straus SE, Straus C, Tzanetos K. Under the auspices of the International Campaign to Revitalise Academic Medicine. Career Choice in Academic Medicine: systematic review. J Gen Intern Med. 2006;21(12):1222-9.

23. Horn L, Tzanetos K, Thorpe K, Straus SE. Factors associated with the subspecialty choices of internal medicine residents in Canada. BMC Med Educ. 2008; 8(37).

24. Collins J. Foundation for Excellence: An evaluation of the Foundation Programme. 2010. Medical Education England.

25. Albert M. P-830 - The influence of medical school placement on psychiatry as a speciality career choice. Eur Psychiatry. 2012;27(Supplement 1(0)):1.

26. McManus IC, Keeling A, Paice E. Stress, burnout and doctors' attitudes to work are determined by personality and learning style: a twelve year longitudinal study of UK medical graduates. BMC Med. 2004;2:29.

27. Ferguson $E$, James $D$, Madeley L. Factors associated with success in medical school: systematic review of the literature. BMJ. 2002; 324 http://dx.doi.org/ 10.1136/bmj.324.7343.952

28. Woolf K, McManus IC, Potts HWW, Dacre J. The mediators of minority ethnic underperformance in final medical school examinations. Br J Educ Psychol. 2013:83(Pt 1):135-59. doi:10.1111/j.2044-8279.2011.02060.x.

29. Fazel S, Ebmeier KP. Specialty choice in UK junior doctors: Is psychiatry the least popular specialty for UK and international medical graduates? BMC Med Educ. 2009;9:77. doi:10.1186/1472-6920-9-77.

30. Royal College of Psychiatrists Recruitment Strategy 2011-2016 (Updated 10th February 2012). 2012. Royal College of Psychiatrists, London. http://www. rcpsych.ac.uk/pdf/Recruitment\%20Strategy\%20-\%2010092013.pdf

31. Goldacre MJ, Turner G, Fazel S, Lamber T. Career choices for psychiatry: national surveys of graduates of 1974-2000 from UK medical schools. Br J Psychiatry. 2005;186(2):158-64.

\section{Submit your next manuscript to BioMed Central and take full advantage of:}

- Convenient online submission

- Thorough peer review

- No space constraints or color figure charges

- Immediate publication on acceptance

- Inclusion in PubMed, CAS, Scopus and Google Scholar

- Research which is freely available for redistribution

Submit your manuscript at www.biomedcentral.com/submit 